\title{
Investigation of Ionospheric Storms Occurred over Turkey during a Geomagnetic Storm
}

\author{
Ramazan Atici \\ Faculty of Education, Mus Alparslan University, Mus 49250, Turkey \\ E-mail: r.atici@alparslan.edu.tr
}

\begin{abstract}
In this study, the observed ionospheric storms over Turkey during severe geomagnetic storm occurred in 27 to 28 May 2017 was investigated by using six stations in the TUSAGA-Active GPS network. Dst and $\mathrm{Kp}$ indices were used to determine the state of the geomagnetic storm, while ionospheric storms were investigated by means of total electron content. The analysis shows that the negative ionospheric storms have been shown to occur during initial and main phase of this storm. However, a positive ionospheric storm occurred during the return phase of the storm. According to statistical analysis, it can be stated that ionospheric storms weaken as they move from west to east and from south to north.
\end{abstract}

Keywords: Geomagnetic storms, Ionospheric storm, TUSAGA-Active, TEC

DOI: $10.7176 / J S T R / 5-12-33$

\section{Introduction}

The response of the Earth ionosphere to geomagnetic storms caused by severe solar flares is one of the most important issues for understanding the variation of the ionosphere with time and location and improving the modeling and prediction of ionospheric activities. This is of vital important for many systems that use radio communication, satellite navigation, radar detection and trans-ionospheric electromagnetic wave signals (Atıcı and Sağır, 2017; Rishbeth and Garriott, 1969; Sağır and Atıcı, 2018; Sağır et al., 2015). The strength of a geomagnetic storm is characterized by a minimum Dst (Disturbancestorm time) index (Gonzalez et al., 1994). Based on this parameter, geomagnetic storms can be classified as: Small Storm (Dst $\leq-30 \mathrm{nT})$, moderate storms (Dst $\leq-50 \mathrm{nT})$, dense storm (Dst $\leq-100 \mathrm{nT}$ ) and large storm (Dst $\leq-200 n T)($ Imtiaz et al., 2019; Loewe and Prölss, 1997; Tsurutani et al., 1992).

Geomagnetic storms cause disturbances in the Earth's magnetic field, resulting in various inhomogeneous processes in the Earth's ionosphere. The presence of ionospheric irregularities during geomagnetic storms is confirmed by numerous observations (Atıcı and Sağır, 2019; Buonsanto, 1999; Gonzalez et al., 1994; Prölss et al., 1991). However, the physical structure of many mechanisms is still not clear enough. An ionospheric disturbance is still the most complex phenomenon in the upper atmosphere (Buonsanto, 1999; Gonzalez et al., 1994; Gulyaeva and Arikan, 2017; Karatay et al., 2010; Lastovicka, 2002). The ionospheric effects of geomagnetic storms depend mainly on local time, latitude, season, solar activity phase, storm intensity, and many other factors. Ionospheric storms are becoming increasingly important to the lives of companies and ordinary citizens of our planet. These storms cause power outages in electrical power networks, damage to satellites due to high energy particles, increased risk of exposure to radiation in space and high altitude aircraft, changes in atmospheric drag in satellites, errors to Global Positioning System (GPS) and VLF navigation systems, loss of HF communications and to fail UHF satellite connections due to scintillations.

This study investigates the response to ionosphere of Turkey, located in the mid-latitude region, to severe geomagnetic storm on May 24-29, 2017. TEC values in this date above were obtained by using IONOLAB-TEC software for six stations on the Turkey National GPS Network. The remainder of this article is organized as follows: Section 2 deals with the definition of data sets used in our analysis. In Section 3, we presents a general discussion of our results and findings. Finally, the conclusions of this study are presented.

\section{Data sets}

Dst and Kp indices were used to describe the development of geomagnetic storm. The geomagnetic three- 
hour Kp index was introduced by J. Bartels in 1949 and was derived from the standard K index (Ks) of the 13 magnetic field observatories. It is designed to measure the magnetic effects of solar particle radiation and is today considered as a surrogate for energy input from the solar wind into the Earth. Kp is an excellent indicator of the distortion of the Earth's magnetic field and is used by space air to determine whether geomagnetic warnings should be given to users affected by these disturbances. A warning about a geomagnetic perturbation may be given when the Kp value reaches 4 and above. Disturbance Storm Time (Dst) equatorial magnetic distortion indices are obtained from hourly scales of low latitude horizontal magnetic variation. It shows the effect of the high-altitude equatorial ring current flowing towards the globally symmetrical west. The Dst index is a magnetic activity index derived from a geomagnetic observation network near the equator that measures the density of the spherically symmetrical equatorial electrode ("ring current"). Both data sets were obtained from NASA on 24-29 May 2017 using the OMNIWeb web interface provided by NASA (https://omniweb.gsfc. nasa.gov/form/dx1.html).

Ionospheric total electron content (TEC) data under storm conditions were obtained by using estimation algorithm developed by Hacettepe University Ionosphere Research Laboratory (IONOLAB) (Nayir et al., 2007; Sezen et al., 2013). TEC is defined as the line integral of electrons present along an L path between the satellite and the receiver. This value represents the total number of electrons along a cylinder with a square meter area and is measured in TECU units equal to $10^{16} \mathrm{el} / \mathrm{m}^{2}$.

\section{Results and Discussions}

In the present study, the ionospheric storms were investigated by using the ionospheric TEC values obtained for six stations in Turkey's National GNSS Network (TUSAGA-active) during severe geomagnetic storm occurred in Turkey on 27-28 May 2017. TEC values were obtained by using IONOLAB TEC software provided by Hacettepe University Department of Electrical and Electronics Engineering. With this software, raw data in RINEX format of $30 \mathrm{~s}$ downloaded from TUSAGA-Active network was used to obtain vertical TEC values. For the study, the TEC changes in the ionosphere over Turkey in the days of quiet (24-26 May 2017) and disturbed (27-29 May 2017) were examined. Interpretations about ionospheric storms were made by comparing TEC changes in disturbed days with TEC values in quiet days. In addition, the maximum and minimum difference values were obtained for each station by subtracting the TEC values on quiet days from the TEC values on disturbed days. The values obtained and other information about the stations used in the study are shown in Table 1.

This geomagnetic storm, which occurred during the declining period of the 24th Sun period, is a severe geomagnetic storm. There were no significant changes in both Dst and Kp values on quiet days. It is seen that the value of Dst index increased from $6 \mathrm{nT}$ to $14 \mathrm{nT}$ at approximately 15:00 UT on May 27, 2017 and to $43 \mathrm{nT}$ at 21:00 UT on disturbed days. This increase in Dst index is expressed as storm sudden commencement (SSC). After this time, the Dst index began to decrease and the lowest value of $-125 \mathrm{nT}$ was obtained at approximately 07:00 UT on May 28, 2017. Dst value started to increase again after the lowest value. Geomagnetic Kp index ranged from 0 to 2, but increased to 7 during the hours when the storm started. Figure 1 shows the geomagnetic conditions from 24 to 29 May 2017.

Table 1. The coordinates of the TUSAGA-Active stations used in the study and the minimum and maximum values of the TEC differences on the quiet and disturbed days of the stations.

\begin{tabular}{lllll}
\hline Station & $\begin{array}{l}\text { Latitude } \\
(\mathbf{N})\end{array}$ & $\begin{array}{l}\text { Longitude } \\
(\mathbf{E})\end{array}$ & $\begin{array}{l}\text { Min. Diff. } \\
(\mathbf{T E C U})\end{array}$ & $\begin{array}{l}\text { Max. Diff. } \\
\text { (TECU) }\end{array}$ \\
\hline ISTN & 40.59 & 28.49 & -8.50 & 5.16 \\
DATC & 36.42 & 27.41 & -10.22 & 4.94 \\
BOYT & 41.27 & 34.47 & -7.53 & 5.47 \\
MRSI & 36.46 & 34.36 & -7.96 & 4.84 \\
TRBN & 41.00 & 39.42 & -7.63 & 4.67 \\
MARD & 37.18 & 40.43 & -7.46 & 3.42 \\
\hline
\end{tabular}




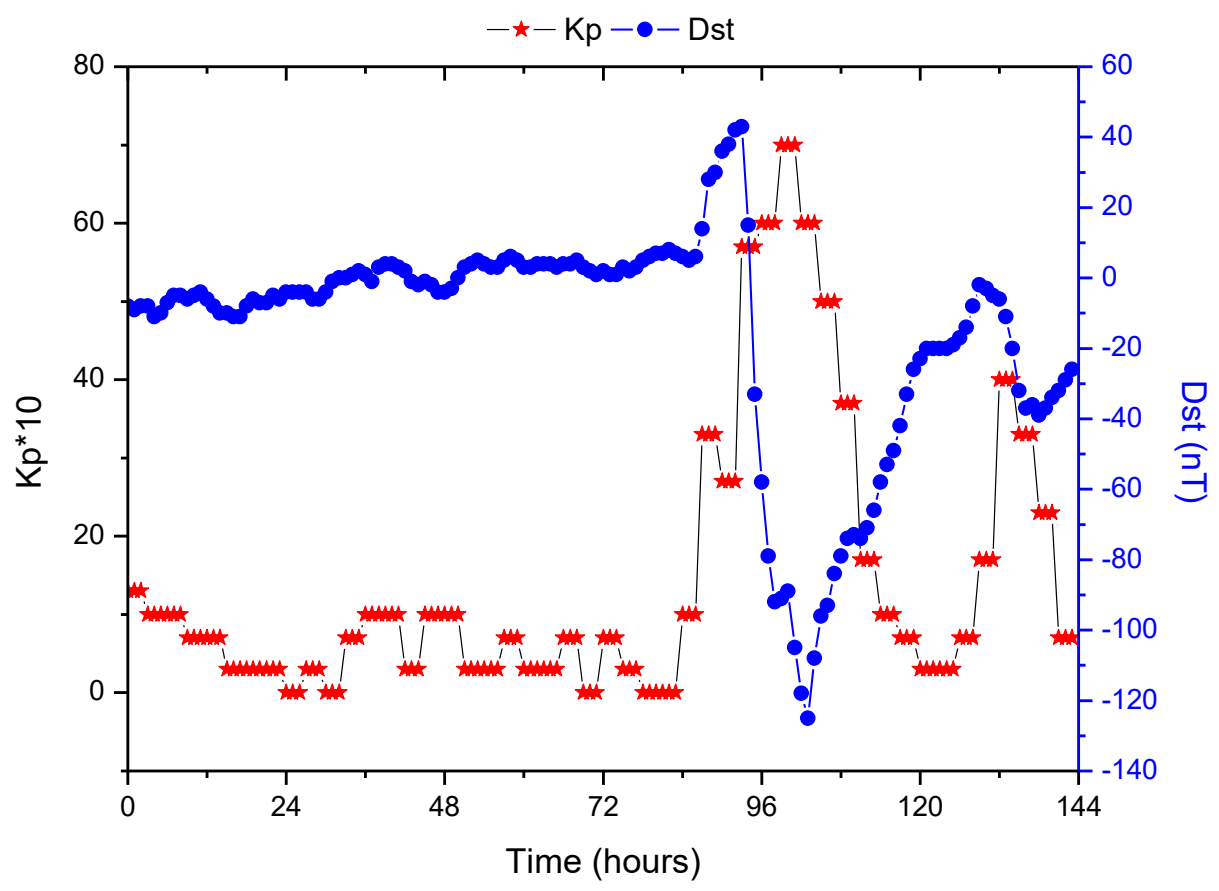

Figure 1. Change of Kp and Dst indices during 24-29 May 2017 covering the geomagnetic storm on 27-28 May 2017. The blue circles indicate the change in the Dst index and the red stars indicate the change in the Kp index.
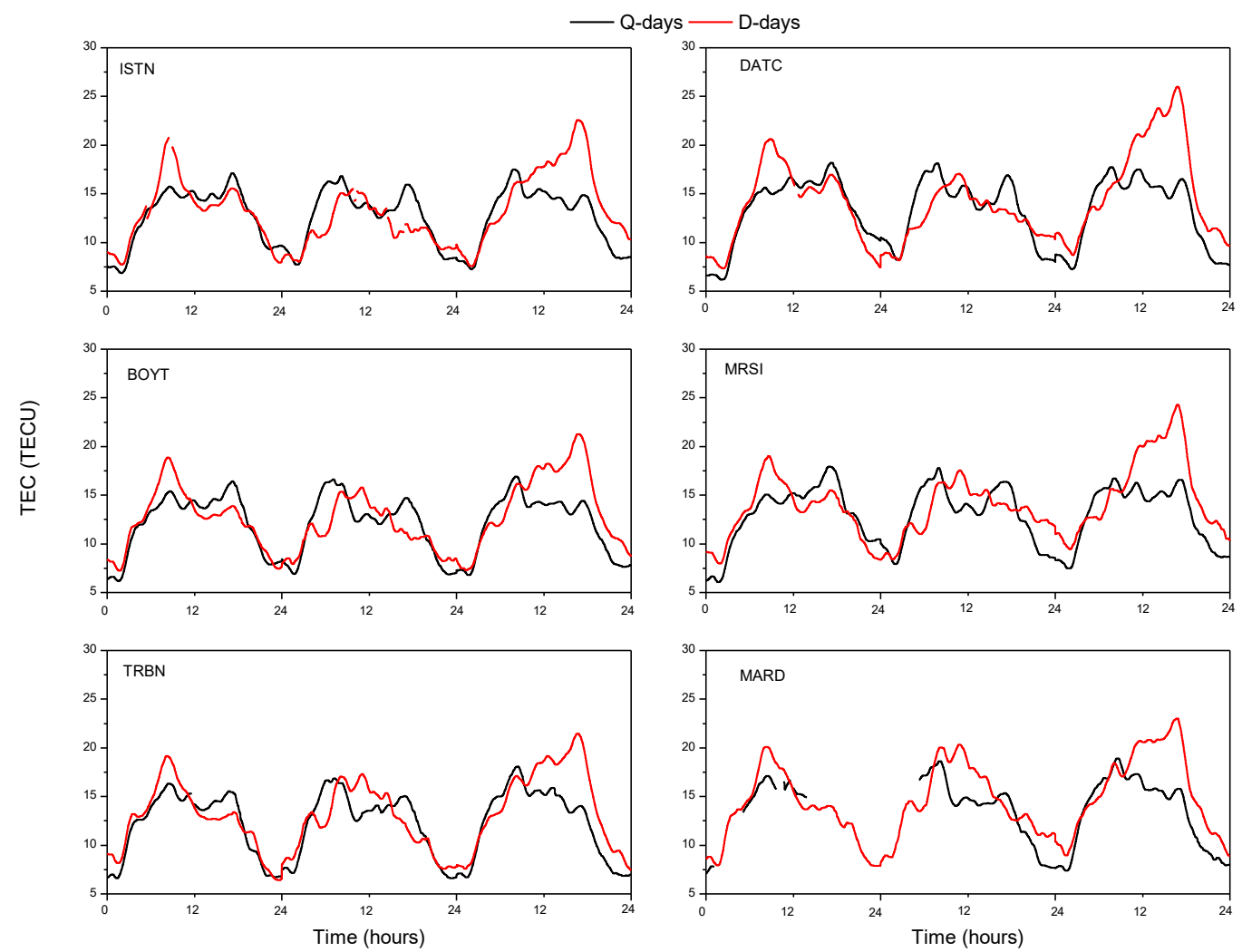

Figure 2. The change in the TEC value obtained from the stations of the TUSAGA-Active network during 24-29 May 2017 covering the geomagnetic storm on 27-28 May 2017. The black solid line shows the change of TEC values over time in quiet days (24-26 May 2017), while the red straight line shows the change in the TEC values during disturbed days (27-29 May 2017). 
After obtaining the TEC values for the six stations given in Table 1, TEC changes in quiet and disturbed days are given in Figure 2. During the geomagnetic storm, there are two phases of the storm that occur in the ionosphere, negative and positive (Buonsanto, 1999). In the negative ionospheric storm process, a significant decrease in ionospheric electron density is observed, while an increase is observed in positive storm. Before the storm, TEC values in all stations, especially in the morning hours, are approximately 3-5 TECUs higher than the quiet day (on May 24) on disturbed day (on May 27). This increase in disturbed days indicates a positive ionospheric storm before the storm. It is seen that TEC values generally decrease in the beginning and main phases of the storm after morning hours on the same day. The largest decrease occurred at DATC station with -10.22 TECU, then at ISTN station with -8.50 TECU. However, the lowest reduction was observed at the MARD station. In the early hours of the storm return phase, the TEC changes on quiet and disturbed days are very close each other. However, there was a noticeable increase in TEC values at all stations at afternoon. This increase in the afternoon at all stations indicates a positive ionospheric storm.

\section{Conclusions}

The ionosphere perturbations occurring in Turkey located in the middle latitudes have both negative and positive phases. Thus, according to the results obtained in this study, the disturbances over Turkey' ionosphere is negative in the beginning and main phases of the geomagnetic storm and is positive in the return phase of the geomagnetic storm. These results are consistent with the literature (Imtiaz et al., 2019). However, this research can be expanded by using more stations from the TUSAGA-Active network in more storm periods to obtain clearer information.

\section{References}

Atıc1, R., and Sağır, S. (2017). The effect of QBO on foE. Advances in Space Research 60, 357-362.

Atıcı, R., and Sağır, S. (2019). Global investigation of the ionospheric irregularities during the severe geomagnetic storm on September 7-8, 2017. Geodesy and Geodynamics Available online 28 June 2019.

Buonsanto, M. J. (1999). Ionospheric storms-A review. Space Science Reviews 88, 563-601.

Gonzalez, W., Joselyn, J. A., Kamide, Y., Kroehl, H. W., Rostoker, G., Tsurutani, B., and Vasyliunas, V. (1994). What is a geomagnetic storm? Journal of Geophysical Research: Space Physics 99, 5771-5792.

Gulyaeva, T., and Arikan, F. (2017). Statistical discrimination of global post-seismic ionosphere effects under geomagnetic quiet and storm conditions. Geomatics, Natural Hazards and Risk 8, 509-524.

Imtiaz, N., Younas, W., and Khan, M. (2019). Response of low to mid latitude ionosphere to the Geomagnetic storm of September 2017. Annales Geophysicae Discussions 2019, 1-14.

Karatay, S., Arikan, F., and Arikan, O. (2010). Investigation of total electron content variability due to seismic and geomagnetic disturbances in the ionosphere. Radio Science 45, 1-12.

Lastovicka, J. (2002). Monitoring and forecasting of ionospheric space weather-effects of geomagnetic storms. Journal of Atmospheric and Solar-Terrestrial Physics 64, 697-705.

Loewe, C., and Prölss, G. (1997). Classification and mean behavior of magnetic storms. Journal of Geophysical Research: Space Physics 102, 14209-14213.

Nayir, H., Arikan, F., Arikan, O., and Erol, C. (2007). Total electron content estimation with Reg-Est. Journal of Geophysical Research: Space Physics 112. 
Prölss, G., Brace, L., Mayr, H., Carignan, G., Killeen, T., and Klobuchar, J. (1991). Ionospheric storm effects at subauroral latitudes: A case study. Journal of Geophysical Research: Space Physics 96, $1275-1288$.

Rishbeth, H., and Garriott, O. K. (1969). "Introduction to ionospheric physics," Academic press New York.

Sağır, S., and Atıcı, R. (2018). Comparison of the QBO and F10. 7 Solar Flux Effects on Total Mass Density. Geomagnetism and Aeronomy 58, 841-845.

Sağır, S., Atıcı, R., Özcan, O., and Yüksel, N. (2015). The effect of the stratospheric QBO on the neutral density of the D region. Annals of Geophysics 58, 0331.

Sezen, U., Arikan, F., Arikan, O., Ugurlu, O., and Sadeghimorad, A. (2013). Online, automatic, nearreal time estimation of GPS-TEC: IONOLAB-TEC. Space Weather 11, 297-305.

Tsurutani, B. T., Gonzalez, W. D., Tang, F., and Lee, Y. T. (1992). Great magnetic storms. Geophysical Research Letters 19, 73-76. 